\title{
Liver Resections Combined with Closure of Loop Ileostomies: A Retrospective Analysis
}

\author{
Jeffrey T. Lordan, Angela T. Riga, and Nariman D. Karanjia \\ Regional Hepato-Pancreatico-Biliary Unit for Surrey and Sussex, The Royal Surrey County Hospital, Egerton Road, \\ Guildford, Surrey GU2 7XX, UK
}

Correspondence should be addressed to Jeffrey T. Lordan, dr_lordan@yahoo.co.uk

Received 6 August 2008; Accepted 30 October 2008

Recommended by Olivier Farges

Background. The management of patients with colorectal liver metastases and loop ileostomies remains controversial. This study was performed to assess the outcome of combined liver resection and loop ileostomy closure. Methods. Analysis of prospectively collected perioperative data, including morbidity and mortality, of 283 consecutive hepatectomies for colorectal liver metastases was undertaken. Consecutive liver resections were performed from 1996 to 2006 in one centre by a single surgeon (NDK). Fourteen of these patients had combined liver resection and ileostomy closure. Case-matched analysis was undertaken. Results. Six (2.2\%) patients died in the hepatectomy only group and none died in the combined group. There was no difference in operative blood loss between the two groups (0.09). Perioperative morbidity was $36 \%$ in the combined group and $23 \%$ in the hepatectomy alone group $(P=0.33)$. Mean hospital stay was 14 days in the combined group and 11 days in the hepatectomy only group $(P=0.046)$. Case-matched analysis showed a significant increase in hospital stay $(P=0.03)$ and complications $(P=0.049)$ in the combined group. Conclusion. In patients with CRLM, combined liver resection and closure of ileostomy may be associated with a higher operative morbidity and a prolonged hospital stay.

Copyright (C) 2008 Jeffrey T. Lordan et al. This is an open access article distributed under the Creative Commons Attribution License, which permits unrestricted use, distribution, and reproduction in any medium, provided the original work is properly cited.

\section{INTRODUCTION}

Colorectal cancer is the second leading cause of cancer death in the Western world $[1,2]$. A quarter of the patients with colorectal cancer have liver metastases at presentation and $40 \%$ go on to develop liver metastases at a later stage $[3,4]$. Liver resection remains the only potentially curative treatment for colorectal liver metastases (CRLM) [2-4]. Liver resections taking place in specialised high-volume centres are well-tolerated procedures with low morbidity and mortality.

A number of patients with low-rectal cancers undergo anterior resection with defunctioning loop ileostomy [5]. The closure of loop ileostomies is a reasonably straightforward procedure with low mortality and morbidity and short hospital stay [5].

The aim of the study was to look at the impact of concomitant loop ileostomy closures on the perioperative morbidity and length of hospital stay after a liver resection.

\section{MATERIALS AND METHODS}

An analysis of 283 consecutive hepatic resections for CRLM, undertaken between September 1996 and August 2006, was performed. Data were collected and analysed prospectively by a dedicated whole-time data clerk.

All patients had a staging laparoscopy and intraoperative ultrasonography. Postoperative analgesia was achieved with thoracic epidural.

Perioperative mortality was defined as death during the same hospital admission or within 30 days of the date of the operation if the patient was discharged earlier. Postoperative complications were classified as cardiac, respiratory, renal, hepatic impairment, thromboembolic, sepsis, and wound infections.

All loop ileostomies were closed using interrupted sutures. In patients who underwent concomitant liver resection and ileostomy closure, no other procedures were performed. 
TABle 1: Patients' demographics and operative outcomes.

\begin{tabular}{|c|c|c|c|}
\hline & Hepatic resection alone $(n=269)$ & Hepatic resection + loop stoma closure $(n=14)$ & $P$-value \\
\hline Male:female & $2.2: 1$ & $1.8: 1$ & $\mathrm{~N} / \mathrm{A}$ \\
\hline Mean age/years (range) & $66.5(33$ to 85.4$)$ & $62(42$ to 73$)$ & .13 \\
\hline \multicolumn{4}{|l|}{ ASA } \\
\hline (i) 1 & $51(19 \%)$ & $5(36 \%)$ & \multirow{4}{*}{ N/A } \\
\hline (ii) 2 & $148(55 \%)$ & $6(43 \%)$ & \\
\hline (iii) $3 / 4$ & $36(13 \%)$ & 0 & \\
\hline (iv) Not recorded & $34(13 \%)$ & $3(21 \%)$ & \\
\hline \multicolumn{4}{|l|}{ Type of liver resection } \\
\hline (i) Hemihepatectomy & $95(35 \%)$ & $6(43 \%)$ & \multirow{3}{*}{ N/A } \\
\hline (ii) Extended hemihepatectomy & $67(25 \%)$ & $4(29 \%)$ & \\
\hline (iii) Parenchymal sparing resection & $107(40 \%)$ & $4(29 \%)$ & \\
\hline
\end{tabular}

Number and distribution of liver metastases

\begin{tabular}{|c|c|c|c|}
\hline (i) 1 & 125 & 8 & \multirow{7}{*}{ N/A } \\
\hline (ii) 2 & 61 & 2 & \\
\hline (iii) 3 & 33 & 3 & \\
\hline (iv) 4 & 16 & 1 & \\
\hline (v) $>4$ & 22 & 0 & \\
\hline (vi) Bilateral liver mets & 54 & 0 & \\
\hline (vii) Complete response to chemotherapy & 12 & 0 & \\
\hline Repeat resections & 12 & 0 & $<.0001$ \\
\hline Maximum tumours size/mm & $31.5(3$ to 165$)$ & $28.5(5$ to 85$)$ & .16 \\
\hline Mean blood loss/mL (range) & $262(0$ to 2500$)$ & $219.2(0$ to 2100$)$ & .09 \\
\hline Mean hospital stay/days (range) & $11(3$ to 53$)$ & $14(8$ to 23$)$ & .046 \\
\hline
\end{tabular}

ASA = American Society of Anesthesiologists.

TABle 2: Perioperative complications.

\begin{tabular}{lcc}
\hline Complication & Hepatic resection alone $(n=269)$ & Hepatic resection + loop stoma closure $(n=14)$ \\
\hline Cardiac & 14 & 0 \\
Respiratory chest infection & 7 & 1 \\
Respiratory failure & 7 & 0 \\
Renal & 3 & 0 \\
Liver insufficiency & 5 & 0 \\
Thromboembolic & 1 & 0 \\
Sepsis & 5 & 0 \\
Intestinal obstruction & 0 & 1 \\
Deep wound infection & 9 & 2 \\
Bile leak & 11 & 1 \\
Total (\%) & $62(23 \%)$ & $5(36 \%)$ \\
\hline
\end{tabular}

$P=.33$.

Due to the discrepancy in the number of patients between the two groups, a case-matched analysis was carried out. This directly compared the patients who underwent concomitant loop ileostomy closure and liver resection versus an equal number of patients who underwent liver resection alone. The patients who underwent liver resection alone were matched for type of liver resection, age, and American Society of Anesthesiologists (ASA). They also had loop ileostomies that had been formed at their primary colorectal resection which were reversed at a separate time to the liver resection.
Chi-squared and $t$-tests were used to analyse data. $P$ value less than .05 was considered to be significant.

\section{RESULTS}

Of the 283 patients undergoing liver resection for CRLM, 14 had a combined liver resection and concomitant loop ileostomy closure. The median time from the formation of loop ileostomy to closure was 252 days (range 68 to 662 days). 
TABLE 3: Case-matched analysis.

\begin{tabular}{|c|c|c|c|}
\hline & Hepatic resection alone $(n=14)$ & Hepatic resection + loop stoma closure $(n=14)$ & $P$-value \\
\hline Male:female & $2.6: 1$ & $1.8: 1$ & N/A \\
\hline Mean age/years (range) & 59.7 (34 to 77$)$ & $62(42$ to 73$)$ & 6 \\
\hline \multicolumn{4}{|l|}{ ASA } \\
\hline (i) 1 & $5(36 \%)$ & $5(36 \%)$ & \multirow{4}{*}{$\mathrm{N} / \mathrm{A}$} \\
\hline (ii) 2 & $6(43 \%)$ & $6(43 \%)$ & \\
\hline (iii) $3 / 4$ & $2(14 \%)$ & 0 & \\
\hline (iv) Not recorded & $1(7 \%)$ & $3(21 \%)$ & \\
\hline \multicolumn{4}{|l|}{ Type of liver resection } \\
\hline (i) Hemihepatectomy & $6(43 \%)$ & $6(43 \%)$ & \multirow{3}{*}{ N/A } \\
\hline (ii) Extended hemihepatectomy & $3(21 \%)$ & $4(29 \%)$ & \\
\hline (iii) Parenchyma sparing resection & $5(36 \%)$ & $4(29 \%)$ & \\
\hline
\end{tabular}

Number and distribution of liver metastases

\begin{tabular}{|c|c|c|c|}
\hline (i) 1 & 8 & 8 & \\
\hline (ii) 2 & 4 & 2 & \\
\hline (iii) 3 & 1 & 3 & N/A \\
\hline (iv) 4 & 0 & 1 & \\
\hline (v) $>4$ & 1 & 0 & \\
\hline (vi) Bilateral liver mets & 3 & 0 & \\
\hline Maximum tumours size $/ \mathrm{mm}$ & $26.5(4$ to 130$)$ & $28.5(5$ to 85$)$ & .5 \\
\hline Mean blood loss/mL (range) & $216(30$ to 2500$)$ & $219(<20$ to 2100$)$ & .15 \\
\hline Mean hospital stay/days (range) & $11(6$ to 15$)$ & $14(8$ to 23$)$ & .03 \\
\hline Complications & $1(7.1 \%)$ & $5(36 \%)$ & .049 \\
\hline Serious complications (grade III or above) [6] & 0 & $2(14 \%)$ & .13 \\
\hline
\end{tabular}

Table 1 demonstrates patients' demographics and perioperative outcomes. There was no significant difference in age or median blood loss between the two groups $(P=.13$ and .09 , resp.). Hospital stay was longer in the group who had a concomitant liver resection and loop ileostomy closure $(P=.04)$. There was no significant difference in maximum tumour size $(P=.16)$. Hospital stay was significantly longer in the combined group (13 days versus 10 days, $P=.046$ ). The number of repeat resections in the hepatectomy alone group was significantly higher $(P<.0001)$.

Table 2 shows the number and type of perioperative complications. There were $62(23 \%)$ complications in the group who had a liver resection alone compared with 5 (36\%) complications in the concomitant group $(P=.33)$.

However, the number of serious complications (grade III or above, according to the classification of surgical complications [6]) in the group who had a liver resection alone was $18(6.7 \%)$ versus $2(14 \%)$ in the concomitant group $(P=.42)$.

There were $6(2.2 \%)$ postoperative deaths in the hepatectomy group. 3 died due to hepatic insufficiency, 2 due to cardiac complications, and 1 due to sepsis. There were no deaths in the group who had a liver resection and loop ileostomy closure.

Table 3 demonstrates a case-matched analysis of an equal number of patients to the group who had concomitant loop ileostomy closure and liver resection. There was no difference in age, type of liver resection, ASA, number and distribution of liver metastases, maximum tumour size, or blood loss.
Hospital stay was significantly longer in the concomitant group $(P=.03)$ as was the complication rate $(P=.049)$, although serious complication rates were not significantly different $(0.13)$. There were no postoperative deaths in these two groups.

\section{DISCUSSION}

Loop, or defunctioning, ileostomies are often created to minimise the impact of peritoneal sepsis from an anastomotic dehiscence following coloanal or low-colorectal anastomosis [5, 7]. However, it probably does not reduce the incidence of anastomotic leak [5, 8-10]. The patients in this series appear to have had a substantial delay in time from formation to closure compared to the literature $[5,7]$. Loop ileostomy closure is often considered low priority by clinicians $[5,7]$, and it is likely that more consideration was given to treating the liver metastases, with neoadjuvant chemotherapy followed by liver resection.

Patients suitable for hepatectomy often request a closure of their loop ileostomy at the time of liver resection. However, to the authors' knowledge, there is no documented evidence demonstrating the safety of this combined procedure compared with hepatectomy alone.

Anecdotally, it was felt in our institution that loop ileostomy closure combined with liver resection increased morbidity. The analysis of the data shows that there was a substantial increase in complications with the combined procedure, although it did not reach significance, possibly 
due to the low numbers involved. Although there were no postoperative deaths in the group who had the combined procedure, there is an evidence that increased frequency of complications during the perioperative period can be associated with a significantly higher mortality regarding hepatectomy [11]. The analysis of the case-matched series, however, did show a significant increase in complications in the concomitant group, although there was no difference in serious complications [6]. Further evidence of the impact of combining these two procedures was demonstrated by the significant increase in hospital stay both in the overall analysis and the case-matched analysis.

The literature reports perioperative morbidity regarding liver resection for CRLM at 13-37\% [1, 12, 13]. However, complication rates associated with hepatectomy have steadily improved over the years partly due to accurate patient assessment and selection and improved critical care. The mortality in the hepatectomy alone group was $2.2 \%$. In the literature, operative mortality for liver resection has reduced over the years to less than $5 \%$ in experienced centres due to improved patient assessment and selection $[14,15]$. Three of the six patients in our series died due to hepatic insufficiency. This may be related to intraoperative Pringle manoeuvres, or the use of neoadjuvant chemotherapy, which can be associated with nonalcoholic steatohepatitis (NASH) [16].

Recently, articles have reported that loop stoma closure as a procedure in its own right can be associated with a substantial morbidity, and is not necessarily the "easy, lowrisk" procedure it may once have been considered $[17,18]$. This may explain the substantial increase in morbidity in patients undergoing closure of loop ileostomy combined with hepatectomy found in this study. The increased complication rate may also explain the significantly higher hospital stay seen in the group who had the combined procedure.

Although there were differences in outcomes between the two groups, the study is limited not only due to the numbers but also due to the potential difference in disease biology between them. However, a recent study comparing hepatectomy and synchronous colonic resection versus colonic resection alone concluded that combining the procedure significantly increases the hospital stay and morbidity rate, reporting a median hospital stay of 13.9 days and complication rate of 56.3\% [19].

Patients occasionally request that their loop stoma be closed at the time of hepatectomy. In such cases, the risks demonstrated in this article can be presented to patients before making an informed decision.

In conclusion, combined liver resection and concomitant closure of loop ileostomy may be associated with increased perioperative morbidity and prolonged hospital stay.

\section{REFERENCES}

[1] A. McKay, E. Dixon, and M. Taylor, "Current role of radiofrequency ablation for the treatment of colorectal liver metastases," British Journal of Surgery, vol. 93, no. 10, pp. 1192-1201, 2006.

[2] P. C. Simmonds, J. N. Primrose, J. L. Colquitt, O. J. Garden, G. J. Poston, and M. Rees, "Surgical resection of hepatic metastases from colorectal cancer: a systematic review of published studies," British Journal of Cancer, vol. 94, no. 7, pp. 982-999, 2006.

[3] G. H. Ballantyne and J. Quin, "Surgical treatment of liver metastases in patients with colorectal cancer," Cancer, vol. 71, no. 12, pp. 4252-4266, 1993.

[4] M. Rees, G. Plant, and S. Bygrave, "Late results justify resection for multiple hepatic metastases from colorectal cancer," British Journal of Surgery, vol. 84, no. 8, pp. 1136-1140, 1997.

[5] J. T. Lordan, R. Heywood, S. Shirol, and D. P. Edwards, "Following anterior resection for rectal cancer, defunctioning ileostomy closure may be significantly delayed by adjuvant chemotherapy: a retrospective study," Colorectal Disease, vol. 9, no. 5, pp. 420-422, 2007.

[6] D. Dindo, N. Demartines, and P.-A. Clavien, "Classification of surgical complications: a new proposal with evaluation in a cohort of 6336 patients and results of a survey," Annals of Surgery, vol. 240, no. 2, pp. 205-213, 2004.

[7] R. Bakx, O. R. C. Busch, W. A. Bemelman, G. J. Veldink, J. F. M. Slors, and J. J. B. van Lanschot, "Morbidity of temporary loop ileostomies," Digestive Surgery, vol. 21, no. 4, pp. 277281, 2004

[8] T. E. Pakkastie, J. T. Ovaska, E. S. Pekkala, P. E. Luukkonen, and H. J. Järvinen, "A randomised study of colostomies in low colorectal anastomoses," European Journal of Surgery, vol. 163, no. 12, pp. 929-933, 1997.

[9] R. T.-P. Poon, K.-W. Chu, J. W.-C. Ho, C.-W. Chan, W.L. Law, and J. Wong, "Prospective evaluation of selective defunctioning stoma for low anterior resection with total mesorectal excision," World Journal of Surgery, vol. 23, no. 5, pp. 463-468, 1999.

[10] N. D. Karanjia, A. P. Corder, P. Bearn, and R. J. Heald, "Leakage from stapled low anastomosis after total mesorectal excision for carcinoma of the rectum," British Journal of Surgery, vol. 81, no. 8, pp. 1224-1226, 1994.

[11] N. D. Karanjia, J. T. Lordan, N. Quiney, W. J. Fawcett, T. R. Worthington, and J. Remington, "A comparison of right and extended right hepatectomy with all other hepatic resections for colorectal liver metastases: a ten-year study," European Journal of Surgical Oncology. In Press.

[12] M. Lise, P. P. Da Pian, D. Nitti, P. L. Pilati, and C. Prevaldi, "Colorectal metastases to the liver: present status of management," Diseases of the Colon \& Rectum, vol. 33, no. 8, pp. 688694, 1990.

[13] K. Yasui and Y. Shimizu, "Surgical treatment for metastatic malignancies. Anatomical resection of liver metastasis: indications and outcomes," International Journal of Clinical Oncology, vol. 10, no. 2, pp. 86-96, 2005.

[14] A. McKay, E. Dixon, and M. Taylor, "Current role of radiofrequency ablation for the treatment of colorectal liver metastases," British Journal of Surgery, vol. 93, no. 10, pp. 1192-1201, 2006.

[15] R. Goslin, G. Steele Jr., N. Zamcheck, R. Mayer, and J. MacIntyre, "Factors influencing survival in patients with hepatic metastases from adenocarcinoma of the colon or rectum," Diseases of the Colon \& Rectum, vol. 25, no. 8, pp. 749-754, 1982.

[16] J.-N. Vauthey, T. M. Pawlik, D. Ribero, et al., "Chemotherapy regimen predicts steatohepatitis and an increase in 90-day mortality after surgery for hepatic colorectal metastases," Journal of Clinical Oncology, vol. 24, no. 13, pp. 2065-2072, 2006. 
[17] L. A. Williams, P. M. Sagar, P. J. Finan, and D. Burke, "The outcome of loop ileostomy closure: a prospective study," Colorectal Disease, vol. 10, no. 5, pp. 460-464, 2008.

[18] T. Mala and A. Nesbakken, "Morbidity related to the use of a protective stoma in anterior resection for rectal cancer," Colorectal Disease, vol. 10, no. 8, pp. 785-788, 2008.

[19] L. Capussotti, A. Ferrero, L. Viganò, D. Ribero, R. L. Tesoriere, and R. Polastri, "Major liver resections synchronous with colorectal surgery," Annals of Surgical Oncology, vol. 14, no. 1, pp. 195-201, 2007. 


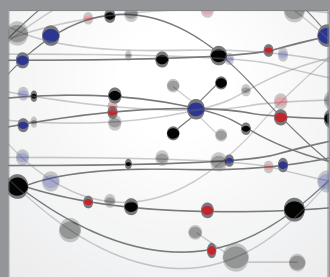

The Scientific World Journal
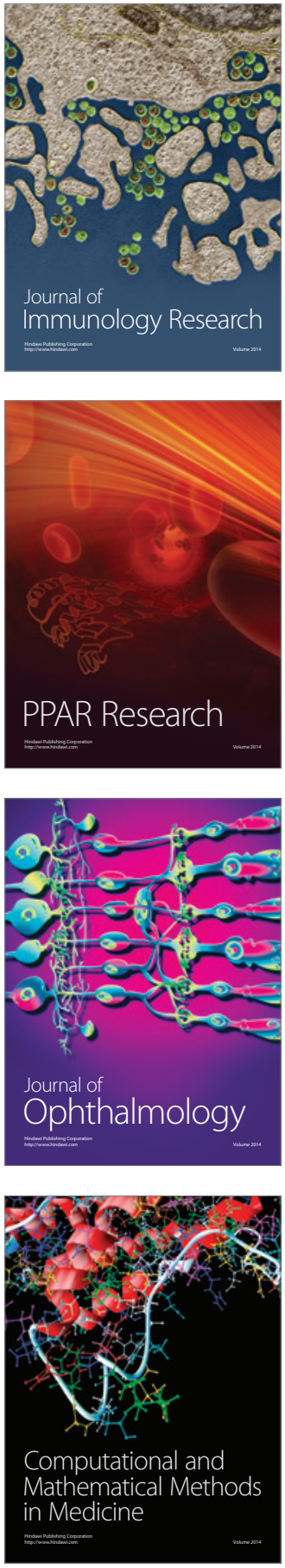

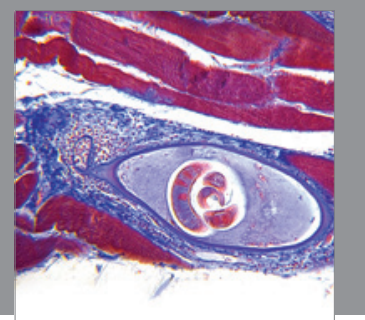

Gastroenterology

Research and Practice
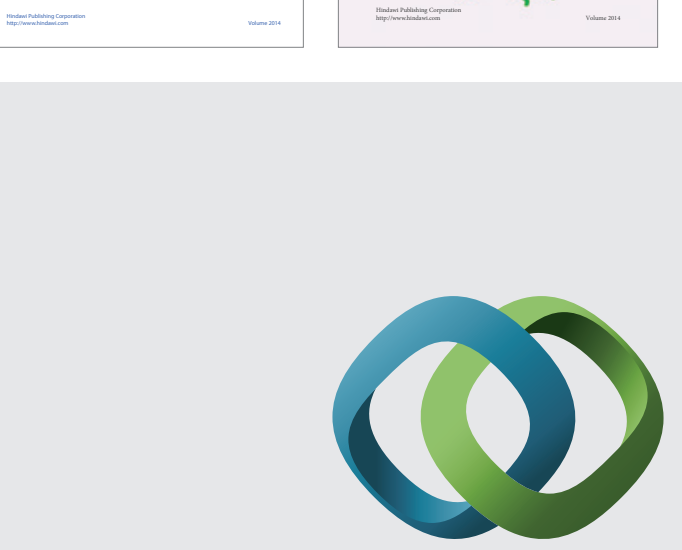

\section{Hindawi}

Submit your manuscripts at

http://www.hindawi.com
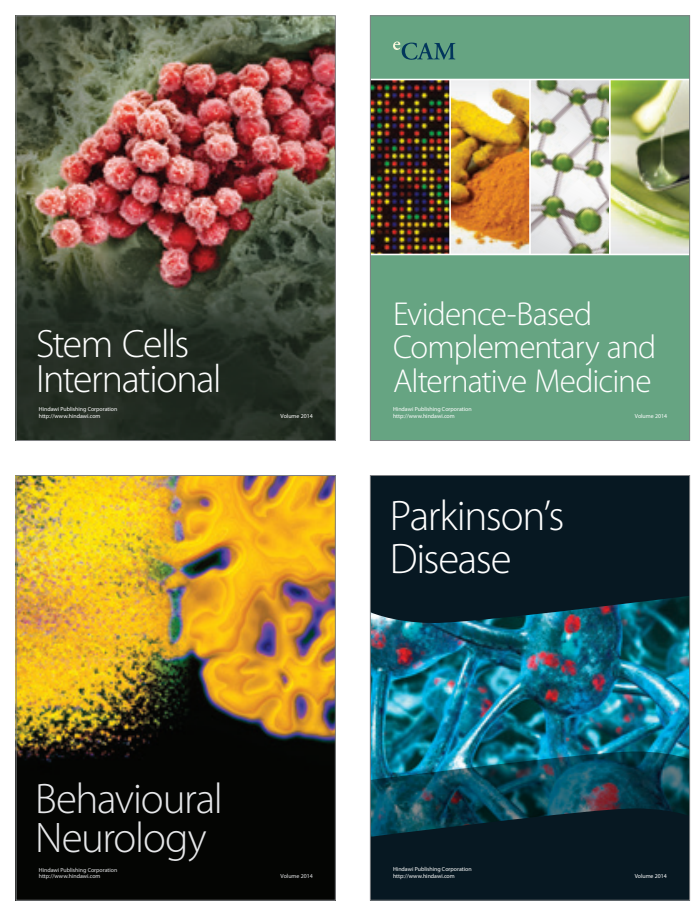

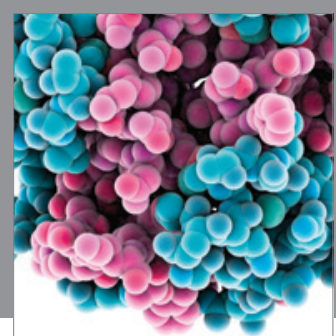

Journal of
Diabetes Research

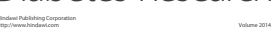

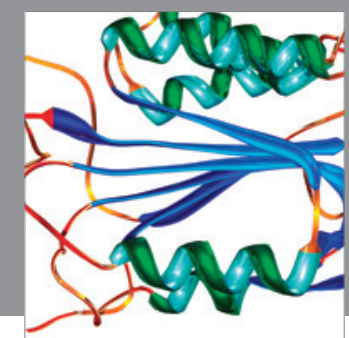

Disease Markers
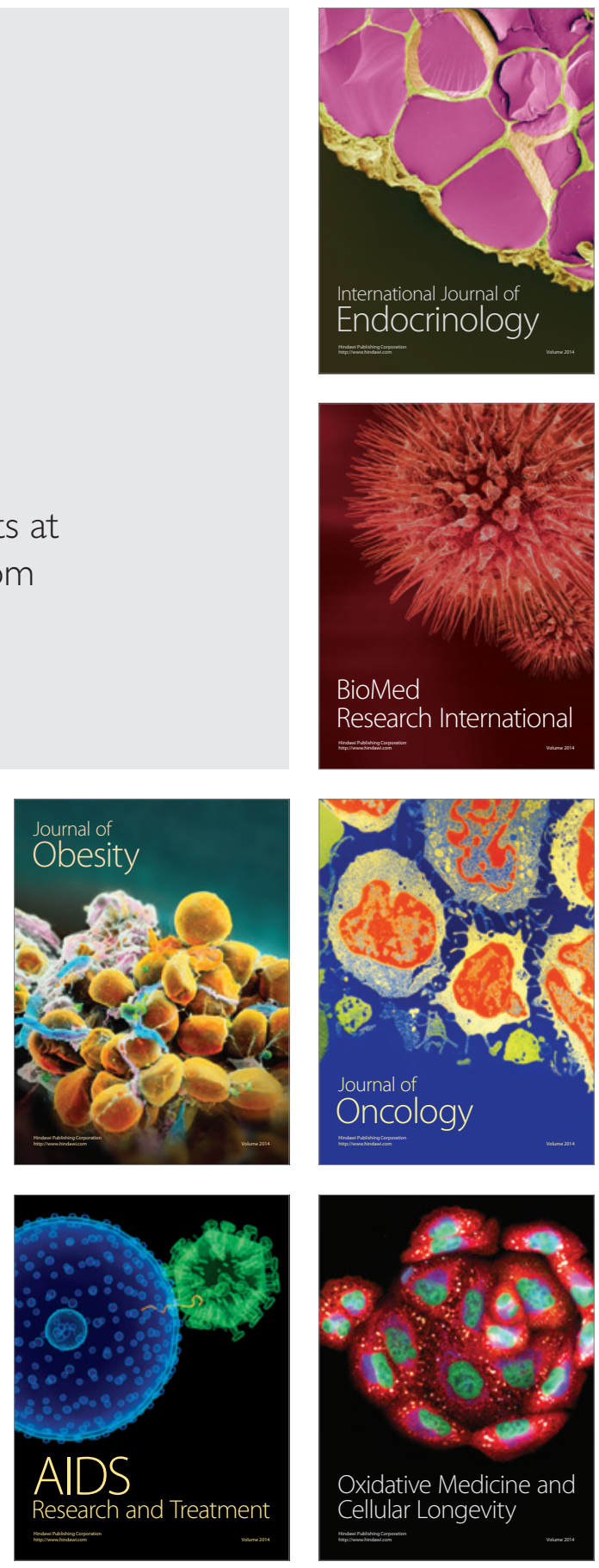